\title{
REVIEWS
}

\section{Cultural Competency Interventions During Medical School: a Scoping Review and Narrative Synthesis}

\author{
Juan R. Deliz, $M D^{\prime}$, Fayola F. Fears, $M D^{7}$, Kai E. Jones, $M D^{7}$, Jenny Tobat, $M D^{7}$, \\ Douglas Char, $\mathrm{MD}^{2}$, and Will R. Ross, MD, MPH
}

'Washington University School of Medicine, St. Louis, MO, USA; 'Department of Emergency Medicine, Washington University School of Medicine, Campus Box 8072, St. Louis, MO, USA; ${ }^{3}$ Division of Nephrology, Department of Medicine, Washington University School of Medicine, St. Louis, MO, USA.

Many medical accreditation bodies agree that medical students should be trained to care for diverse patient populations. However, the teaching methods that medical schools employ to accomplish this goal vary widely. The purpose of this work is to summarize current cultural competency teaching for medical students and their evaluation methods. A scoping review was completed by searching the databases PubMed, Scopus, MedEdPORTAL, and MEDLINE for the search terms "medical education" and "cultural competency" or "cultural competence." Results were summarized using a narrative synthesis technique. One hundred fifty-four articles on cultural competency interventions for medical students were systematically identified from the literature and categorized by teaching methods, length of intervention, and content. Fifty-six articles had a general focus, and ninety-eight articles were focused on specific populations including race/ethnicity, global health, socioeconomic status, language, immigration status, disability, spirituality at the end of life, rurality, and lesbian, gay, bisexual, transgender, and queer. About 54\% of interventions used lectures as a teaching modality, $45 \%$ of the interventions described were mandatory, and $9.7 \%$ of interventions were not formally evaluated. The authors advocate for expansion and more rigorous analysis of teaching methods, teaching philosophies, and outcome evaluations with randomized controlled trials that compare the relative effectiveness of general and population-specific cultural competency interventions.

KEY WORDS: cultural competence; cultural humility; culture; medical education; diversity.

J Gen Intern Med 35(2):568-77

DOI: $10.1007 / \mathrm{s} 11606-019-05417-5$

(C) Society of General Internal Medicine 2019

\section{INTRODUCTION}

Research has shown that perceived sociocultural differences can affect communication and decision making and are directly linked to patient satisfaction, treatment plan adherence, and overall care quality. ${ }^{1-4}$ "Cultural competency" and "cultural

Received February 22, 2019

Revised July 15, 2019

Accepted September 16, 2019

Published online November 8, 2019 humility" have emerged as approaches to addressing these differences in the healthcare system. Cultural competency has been defined as "a set of congruent behaviors, attitudes, and policies that come together in a system, agency, or among professionals and enable... (providers) to work effectively in cross-cultural situations." ${ }^{" 5,6}$ Some argue that cultural competency is an unfeasible goal and that it is unrealistic to set this as a standard for health professionals. Others propose that providers should strive for cultural humility, a set of skills focused on continuous learning and self-reflection on one's interactions with individuals from cultures different from their own. ${ }^{7}$ As cultural competency is an older term and appears more frequently in the literature, the authors use this going forward, acknowledging that many institutions have embraced the term cultural humility.

Healthcare training institutions have the responsibility to cultivate the compassion and humanism needed to produce well-rounded providers. The Liaison Committee on Medical Education (LCME) suggests that the medical curriculum should include teaching on the importance of developing strategies for addressing healthcare disparities, the principles of culturally competent care, and the ways in which culture affects a patient's experience of symptoms, disease, and treatment. ${ }^{8}$ Most accreditation bodies do not provide guidelines on how to accomplish this task, and as such, medical schools have implemented a myriad of teaching and assessment methods related to cultural competency and humility. ${ }^{8,9}$

Prior systematic reviews have examined curricula for healthcare professionals to analyze the impact of cultural competence training. Multiple studies have shown that cultural competency curricula positively changed provider skills, knowledge, and attitudes. Beach et al. ${ }^{10}$ found that there was good evidence that cultural competency interventions improved patient satisfaction, but limited evidence that these interventions led to improvement in health outcomes. The current authors set out to review the cultural competency literature and noticed a lack of studies outlining what topics medical schools were focusing on in their cultural competency interventions. Additionally, there was no standardized conceptual framework to categorize published interventions by length, teaching approaches, or whether the intervention was required for graduation. 
The authors' goal for this work was to review the field of cultural competency curriculum for medical students and to categorize current published practices. The authors hope to identify gaps in the current literature such that medical educators are better equipped to develop deliberate curriculum focused on caring for diverse populations.

\section{METHODS}

A scoping review was completed by searching the databases PubMed, Scopus, MedEdPORTAL, and MEDLINE. The terms used in PubMed were "medical education" AND ("cultural competency" OR "cultural competence"), which yielded 490 articles. Scopus was searched using the terms "medical education" AND ("cultural competency" OR "cultural competence"), yielding 798 articles. MEDLINE was searched using the following: ("Education, Medical"[Mesh] OR "Education, Medical, Undergraduate"[Mesh]) AND "Cultural Competency"[Mesh], for a result of 358 articles. As the term cultural humility is newer, it did not have its own MESH term and it was not included. Finally, MedEdPORTAL was searched using the term cultural competency which yielded 155 articles. This search resulted in 1801 total articles.

The resultant articles were considered eligible if they met the following criteria: (i) written in or translated into English; (ii) published on or prior to December 31, 2017; (iii) had full text accessible online for review; and (iv) described a specific cultural competency intervention targeted to medical students. To reduce selection bias, two reviewers independently reviewed the results from each database to determine the articles that met the inclusion and exclusion criteria (J.R.D. and F.F.). Any discrepancy was discussed with at least one other reviewer and resolved by majority opinion. Reviewers used the inclusion and exclusion criteria to review abstracts, by which 1476 articles were discarded. The remaining 325 articles were reviewed in their entirety. One hundred and seventy-one articles were excluded for not fulfilling the inclusion criteria, and of which, 29 articles were excluded since they did not have full text accessible for review. This resulted in 154 articles fulfilling criteria with full text available, which were included in the analysis of this literature review (Fig. 1).

A modified narrative synthesis format for discussing results was chosen for the conceptual framework as the articles varied in terms of research designs and data outcomes. ${ }^{11,12}$ The stages of the narrative synthesis included the following: (1) developing the preliminary synthesis, (2) comparing themes within and between studies, and (3) thematic classification. The preliminary synthesis included extracting the following data: length of intervention, teaching methods, country of origin, outcome measure, voluntariness of the intervention, type of intervention employed, and summary of main study findings. Interventions were placed into five categories by length: $1-3 \mathrm{~h}$, half day to 1 day, 1 day to 1 week, longer than 1 week, and longitudinal throughout a year or entire

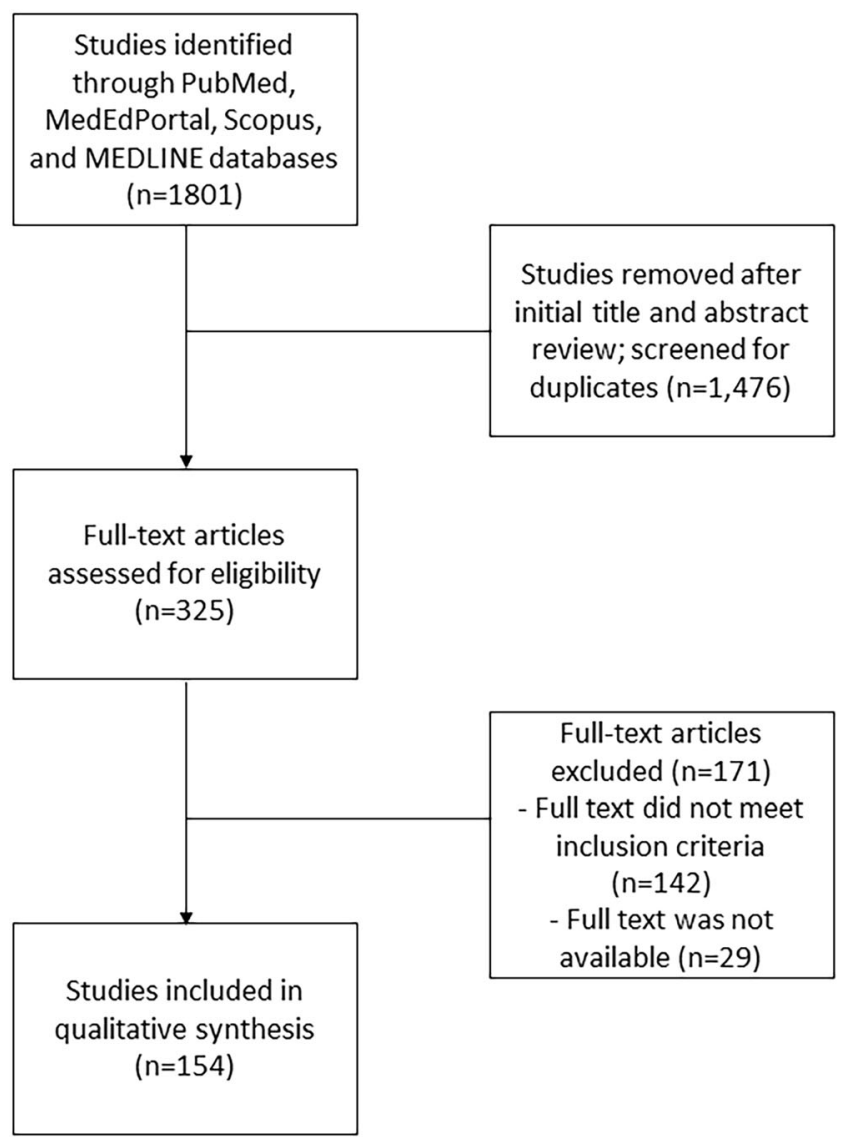

Figure 1 Flow diagram and results of literature review. Using PubMed, MedEdPORTAL, Scopus, and MEDLINE databases, 1801 articles were identified. During screening of titles and abstracts, 1476 were removed based on inclusion and exclusion criteria. One hundred and seventy-one articles were then excluded after full-text review because they did not meet criteria or the full text was not available. One hundred and fifty-four articles were included in final synthesis.

curriculum. Interventions that did not have lengths mentioned were classified as undetermined. Two independent reviewers thematically categorized each study by area of focus (J.R.D. and F.F.). Finally, the authors resolved uncertainties in classification through discussion with multiple reviewers (K.E.J., F.F., J.R.D., J.T.). Studies that were particularly innovative or broadly reflective of the category were highlighted. As many of the selected articles had disparate outcome measures, such as standardized patients' feedback, pre- and post-surveys, and focus groups, the efficacy of interventions was not compared.

\section{RESULTS}

\section{Interventions Identified}

One hundred fifty-four unique articles fulfilled all inclusion criteria (Fig. 1). These were subsequently categorized by teaching methods, length of intervention, topics covered, outcome measure, and voluntariness of participation (Table 1). Topics identified were placed into two major categories, "General" and "Specific Population." Those in the "Specific 
Table 1 Intervention Classification

\begin{tabular}{ll}
\hline \hline & $\begin{array}{l}\text { Number of programs } \\
\text { (\% of total) }\end{array}$ \\
\hline Type of intervention & \\
Lecture & $83(53.9)$ \\
Discussion & $56(36.4)$ \\
Cultural immersion/encounter & $41(26.6)$ \\
Clinical experience & $34(22.1)$ \\
Written reflection & $27(17.5)$ \\
Online module & $26(16.9)$ \\
Standardized patient & $27(17.5)$ \\
Role-play & $20(13.0)$ \\
Reading & $17(11.0)$ \\
Video & $16(10.4)$ \\
Requirement status & $70(45.4)$ \\
Mandatory & $83(53.9)$ \\
Voluntary & \\
Length of intervention & $64(41.6)$ \\
1-h to 3-h event & $12(7.8)$ \\
Half to 1 day & $8(5.2)$ \\
1 day to 1 week & $21(13.6)$ \\
Greater than 1 week but not longitudinal & \\
throughout school year or curriculum & $45(29.2)$ \\
Longitudinal throughout the year or & \\
entire curriculum & $4(2.6)$ \\
Unclear about time course & \\
Evaluation method & $23(14.9)$ \\
Test & $100(64.9)$ \\
Surveys & $16(10.4)$ \\
Standardized patient & $13(8.4)$ \\
Reflective essay & $7(4.5)$ \\
Discussion/focus group & $6(3.9)$ \\
Interview & $1(.6)$ \\
Presentation & $15(9.7)$ \\
None & \\
\hline
\end{tabular}

The 154 articles meeting the inclusion criteria were further characterized based on the type of intervention. Given that many articles employed multiple interventions, percentages will add up to greater than $100 \%$

Population" category were further classified into categories including race/ethnicity, global health, rurality, socioeconomic status, language, refugee/asylum seekers, disability identities/ deaf culture, religion/spirituality at the end of life, and Lesbian, Gay, Bisexual, Transgender, and Queer (LGBTQ). Most interventions utilized lectures to teach students (83/154). Discussion groups were another popular teaching format (56/ 154). Most interventions $(64 / 154)$ were 1 -h to 3 -h events, and $45 / 154$ of interventions were longitudinal. Most of the studies evaluated the intervention (139/154) with many using surveys (100/154) and knowledge-based tests (23/154).

Specific findings for each category are described in the following subsections. Interventions with interesting approaches in their teaching methods, evaluation, or content are also included.

\section{General}

Fifty-six articles were classified as general, which included programs that provided frameworks for communicating with patients of diverse backgrounds, emphasized identifying one's own bias, and/or focused on general principles for addressing sociocultural determinants of health. ${ }^{7,13-66}$ Of the 56 articles, 20 were 1-3-h experiences, six were half day, three were between a day and a week, three were greater than 1 week,
23 were longitudinal activities, and one article did not discuss program length. The most common teaching method was lecture (31/56), followed by discussion (26/56). Other popular teaching methods included written reflections (14/56), roleplay $(11 / 56)$, standardized patient encounters $(10 / 56)$, and online modules $(8 / 56)$. Of the general interventions, 34 were required. Forty-four of the 56 interventions were evaluated: surveys were the most popular form of analysis (34/56), knowledge-based tests $(5 / 56)$, standardized patient encounters $(4 / 56)$, focus groups $(2 / 56)$, and interviews $(2 / 56)$.

In Betancourt and Cervantes, students learned to approach patients by assessing core cross-cultural issues, exploring the meaning of illness, determining social context, and engaging in negotiation. The authors stressed the importance of combining the knowledge of specific cultures with general communication skills that are applicable for diverse patient populations. $^{17}$

Similarly, Dao et al. ${ }^{16}$ sought to avoid the propagation of stereotypes by providing students with a general approach to patients of diverse backgrounds. Students were introduced to fundamental sociomedical themes to help them understand the impact of these factors on patient care. Themes included socioeconomic class, race, gender, LGBTQ issues, "compliance," the medical gaze, faith, and advocacy. ${ }^{16}$

\section{Specific Populations}

Ninety-eight articles were identified that described programs focused on a single population and the sociocultural factors that affect its members' health. These interventions were further subdivided into the following categories: race/ethnicity, global health, socioeconomic status, language, refugee/asylum seekers, disability identities and deaf culture, spirituality at the end of life, rurality, and LGBTQ.

Race/Ethnicity. Twenty articles identified interventions that addressed specific racial/ethnic populations without involving travel abroad. ${ }^{67-86}$ Seventeen of the 20 interventions were developed at US medical schools, while the remainder were from New Zealand, Canada, Australia, Romania, Germany, and Russia. Nine articles focused on populations that were indigenous to the study's country of origin. Seven of the interventions were $1-3 \mathrm{~h}$, one was half day, three were less than 1 week, four were integrated into clerkships, and five were longitudinal experiences. A multitude of teaching methods were employed including lecture (9/20), cultural immersion component $(7 / 20)$, online modules $(6 / 20)$, and videos $(4 / 20)$. Nineteen of the articles evaluated their programs with the majority using surveys. All programs reported positive outcomes including improvement in students' attitudes and acquisition of skills to provide population-specific care.

One Canadian study used videos about the care of Chinese patients and showed that $67.3 \%$ of students had learned useful strategies to better serve immigrant patients. ${ }^{73}$ An overwhelming $79.6 \%$ of respondents stated that online videos could be an 
effective method in cultural competency training. Another article compared two different types of online interventions: a module on interprofessional communication and a patient encounter between a student and a Salvadoran family. ${ }^{74} \mathrm{Stu}-$ dents were evaluated through a standardized patient, and those who were exposed to the virtual patient module outperformed students who were not exposed to the module.

Global Health. Fifteen articles were identified that focused on cultural competency development through global health experiences. ${ }^{87-101}$ Fourteen of these described interventions with cultural immersion outside of one's home country as the main teaching method, with nine of the 14 providing clinical experience. One intervention described a 3 -h course preparing students to complete a global health program. ${ }^{101}$ Eleven of the interventions were 1 month to a semester long, three were longitudinal, and one was $3 \mathrm{~h}$. Additional teaching methods included written reflections $(4 / 15)$, lectures $(6 / 15)$, discussions $(4 / 15)$, online modules (1/15), and videos $(1 / 15)$. None of the international interventions were required for medical students. Most of the articles used surveys to analyze outcomes, although three also used interviews with students and two used a focus group. In those interventions that addressed outcomes, the majority of students rated their program favorably. ${ }^{88-98,100}$

In the study of Nishigori et al. ${ }^{96}$ students participating in an exchange program between the UK and Japan noted that they developed a deeper understanding of different healthcare systems. Mao et al. ${ }^{94}$ reported that students taking an acupuncture and traditional Chinese medicine elective "increased their understanding of the challenges faced by immigrants who try to negotiate the complex healthcare system."

Of note, two of the articles evaluated the effects of their programs with long-term follow-up. Hutchins et al. ${ }^{97}$ showed long-lasting effects in former participants of a One Health trip to Ecuador, especially regarding the use of Spanish language and cross-cultural skills. Jacobs et al. ${ }^{98}$ reported a similar outcome with participants in an exchange program from Germany to Ethiopia after 8 years.

Socioeconomic Status. Six articles were identified specifically addressing issues affecting patients of low socioeconomic status (SES) ${ }^{102-107}$ Five of the interventions were extended clinical experiences, and one was $1-3 \mathrm{~h}$. Four of the six used lectures as a teaching modality, and two used a small group. Standardized Patient (SP) sessions, online modules, and written reflections were also used.

Turner and Farquhar ${ }^{102}$ used an interprofessional curricular program to help students identify and understand the relationship between health conditions and poverty and work to promote the welfare of people who are economically disadvantaged. Students who completed the intervention performed better than students of the prior year on standardized patient encounters and the USMLE Step 2 Clinical Skills Exam. ${ }^{102}$

In the study of Sheu et al., ${ }^{104}$ students volunteered at student-run clinics targeting low-income populations.
Participating students reported improved understanding but did not score differently on validated surveys of sociocultural attitudes when compared to students who did not participate. $^{104}$

Language. Thirteen articles focused on the language barriers affecting clinical care. ${ }^{108-120}$ Five of the interventions were longitudinal, seven of these interventions were 1-3 h, and one was two and a half weeks. Eight out of the 13 interventions were mandatory. Almost all interventions included opportunities for students to practice their communication skills, whether through role-play, clinical experiences, online modules, or standardized patient encounters. Three interventions also consisted of a lecture on working with interpreters. Most of the articles described positive results and good student reviews. Nevertheless, one article found that almost $40 \%$ of students failed to use interpreters in an encounter with a patient of limited English proficiency. ${ }^{111}$

Zanetti et al. ${ }^{115}$ described a 4-year program that promotes cultural competency through civic engagement and second language fluency. Students who participated reported greater confidence in obtaining a medical history in a different language, advocating for the healthcare needs of underserved populations, and assessing the health beliefs and practice of patients from other cultures. ${ }^{115}$

Refugees or Asylum Seekers. Six articles which discussed interventions were aimed at populations of refugees or asylum seekers. ${ }^{121-126}$ One article described a 1-3-h intervention, one was a full day, three were longitudinal, and one did not specify time course. Most used lectures and clinical experiences as teaching methods. Evaluation methods included surveys and essays. Asgary et al. ${ }^{121}$ taught students about asylum law through a series of lectures, workshops, and clinical sessions. This intervention made use of hands-on work preparing medical affidavits to help patients receive governmental services of which $89 \%$ were accepted in court. The students improved their attitudes toward asylum seekers, knowledge of effects of torture, and efficacy in clinical evaluation. ${ }^{121}$

Disability Identities and Deaf Culture. Ten articles were identified that addressed interventions related to disabilities, a physical or mental impairment that limits the patient's daily activities. ${ }^{127-136}$ Only one of the articles described a longitudinal intervention with three of the ten describing 1-hto 3-h-long programs. The articles emphasized the importance of experience interacting with people with disabilities and developing a greater understanding of the problems they face when accessing healthcare. Nine of the interventions taught using lectures, two included standardized patient encounters, three used videos, one had an immersive experience, five used clinical experiences, and the last used role-play.

In the study of Thew et al., ${ }^{133}$ medical students attended a lecture and then a role reversal scenario, in which students 
attempted to communicate without speaking to deaf volunteers acting as providers. Students rotated through a doctor's office, a pharmacy, and an emergency department and then discussed their experiences in small groups. This intervention was evaluated with surveys and found improvement in the student's comfort interacting with deaf patients. ${ }^{133}$

Hagood et al. ${ }^{131}$ describes an elective course focusing on the transition from pediatric- to adult-centered care and the impact of chronic illness on independent functioning. Students reported that they appreciated the opportunity to interview caregivers and patients with cystic fibrosis. ${ }^{131}$

Spirituality and End of Life. Seven articles were identified that focused on issues of cultural competency related to religion and spirituality in the palliative care setting. ${ }^{137-143}$ Six of the interventions were 1-3-h experiences, and the last was during a third-year clerkship. All the interventions were voluntary. For teaching methods, three interventions used lectures, two used online modules, and two used role-play. To evaluate program efficacy, two of the seven articles used reflective essays, and three used surveys. The remaining articles used SP exams and knowledge-based tests.

One interdisciplinary intervention employed an online module for students from schools of medicine, social work, nursing, and chaplaincy. Through qualitative analysis of survey responses, the study concluded that students benefited from the program, but that medical students were less comfortable addressing palliative care and religion than students from other programs. The authors propose that medical students might feel less confident because they have less experience with discussions about religion in their standard medical curriculum. ${ }^{142}$

Rurality. Three articles were identified that focused on rural populations, two from the USA and one from Australia. ${ }^{14-146}$ Two of the three interventions were longitudinal, and the last was a week long. All interventions used immersion as a teaching method and were evaluated, using surveys in two interventions and an interview in the other. Daly et al. ${ }^{144}$ placed students in a clinical setting in a rural area for 6 months. After this experience, the investigators conducted interviews with medical students, supervisors, and clinicians. Participants reported improved cultural awareness and personal/professional development and identified potential barriers to practicing in rural communities including academic isolation, geographical issues, and perceived education risk. ${ }^{144}$

LGBTQ. Eighteen articles were identified as focusing on cultural competency training on gender and sexual minorities. ${ }^{14-163}$ Most of the interventions (16/18) were designed as $1-3-\mathrm{h}$ sessions, used lectures as a teaching modality (8/18), and used surveys as an assessment tool (15/ 18). SP sessions were also commonly used to teach and assess students' ability to take an inclusive sexual history. Vanderleest and Galper ${ }^{147}$ describe a mandatory lecture- based intervention that educated second-year students on terms including "transgender," "transsexual," and "transition." The lecture also taught students about how discrimination and bias contribute to transgender health disparities. ${ }^{147}$ In another SP session, students took a social history and discovered that the patient was questioning their sexual orientation and dealing with family pressures. Eighty-seven percent of students rated the session as good or excellent. ${ }^{150}$

\section{DISCUSSION}

Prior reviews have not focused on cultural competency training for medical students specifically and included providers at different levels of training and from different professions. ${ }^{10,164,165}$ This review focuses on medical students and is unique in that it identifies the primary teaching methods, lengths of interventions, topics covered, and evaluation methods used in published cultural competency interventions. Most interventions (54\%) used lectures as a teaching modality, and $64 \%$ of the interventions were about specific populations. Most used some form of evaluation, with almost $65 \%$ using surveys to evaluate student improvement. Of note, about half of the programs were voluntary which introduces selection bias and can affect the student's self-perception of improvement.

As expected, lectures remain the predominant teaching modality in medical school. ${ }^{166}$ It has become increasingly common for medical schools to expand their teaching to include non-traditional modalities such as team-based learning, standardized patients, and simulated patient experiences. ${ }^{166-168}$ As the curricular interventions for cultural competency training develop, medical schools should continue to move beyond lectures to encompass other teaching methods.

The use of computer modules as a teaching modality was explored in several studies. Online modules and virtual patient interactions can be ideal methods to provide students an opportunity to trial different communication techniques in a lowrisk environment. However, no studies directly compare the effectiveness of virtual patients to standardized patient encounters representing a gap in the current medical education literature.

A divide between the philosophies behind general versus specific population-focused interventions became apparent in reviewing the literature. Some authors argue that focusing on factual knowledge of a specific population increases the risk of promoting stereotypes and promotes the idea that one can gain complete understanding of another culture. These authors advocated for programs that focus on one's own biases and learning general strategies for cross-cultural communication. ${ }^{16}$ The efficacy of interventions that focus on specific populations compared to those that employ a more general model should be evaluated through a randomized controlled trial. 
In addition to formally comparing teaching styles, specific interventions should be assessed in a standardized way. The Tool for Assessing Cultural Competence Training (TACCT) was developed by the Association of American Medical Colleges (AAMC) to assess the entire curriculum of an institution. It does not, however, assess skills gained from individual interventions and their specific impact on a student's knowledge and abilities. ${ }^{169}$ Furthermore, the TACCT was not designed to suggest teaching strategies. The development of a separate tool to examine educational goals and student outcomes from individual interventions would be a useful tool for more standardized evaluation of smaller components of curricula. Similarly, Gozu et al. ${ }^{164}$ found that most educators have limited access to objective and standardized evaluation tools for cultural competence training interventions.

Strengths of this study include the number of papers reviewed, the description and analysis of the components of the interventions, and the inclusion of papers from different countries. However, there are several limitations in the present review. First, this review is subject to publication bias, given that the authors are unable to speak to non-published interventions. Second, given the lack of direct comparisons between teaching methods and intervention types, the authors are unable to speak to relative effectiveness. Lastly, cultural competency as both a scholarly concept and search term presents a limitation. Cultural competency as a MESH term may not capture all dimensions of culture and diversity.

\section{CONCLUSIONS}

The available literature describes a myriad of educational interventions for medical students that address the unique obstacles they may face when caring for patients of different backgrounds. The authors advocate for further research into non-traditional modalities, such as low-cost and easily disseminated online modules. Further research should focus on developing standardized assessment tools for these interventions, as well as randomized controlled trials to compare the relative effectiveness of general and population-specific cultural competency interventions.

Acknowledgments: The authors would like to acknowledge the Office of Diversity Programs at Washington University School of Medicine for their support during the development of this manuscript. The authors would also like to acknowledge the contributions of the Medical Education Research Unit at the Office of Medical Student Education at Washington University School of Medicine.

Corresponding Author: Juan R. Deliz, MD; Washington University School of Medicine, 660 S Euclid Ave, CB 8126, St. Louis, MO 63110, USA (e-mail: jdeliz@wustl.edu).

Author Contribution JRD, FFF, KEJ, JT, DC, and WRR all made equal and significant contributions to this manuscript's conception and design and to the analysis and interpretation, drafted and revised the manuscript critically for intellectual content, and approved the final version for publication. All authors agree to be held responsible for all aspects of the work.

\section{Compliance with Ethical Standards:}

Conflict of Interest: The authors declare that they do not have a conflict of interest.

\section{REFERENCES}

1. Nelson A. Unequal treatment: confronting racial and ethnic disparities in health care. J Natl Med Assoc. 2002;94(8):666-668. https://doi.org/ 10.1001/jama.290.18.2487-b.

2. Stewart M, Brown JB, Boon H, Galajda J, Meredith L, Sangster M. Evidence on patient-doctor communication. Cancer Prev Control CPC = Prévention contrôle en cancérologie PCC. 1999;3(1):25-30. https://doi. org/10.1158/1940-6207.PREV-09-A25.

3. McLemore MR, Altman MR, Cooper N, Williams S, Rand L, Franck L. Health care experiences of pregnant, birthing and postnatal women of color at risk for preterm birth. Soc Sci Med. 2018;201:127-135. https:// doi.org/10.1016/j.scog.2018.05.001.

4. De Marco M, Thorburn S, Zhao W. Perceived discrimination during prenatal care, labor, and delivery: An examination of data from the Oregon pregnancy risk assessment monitoring system, 1998-1999, 2000, and 2001. Am J Public Health. 2008;98(10):1818-1821. https:// doi.org/10.2105/AJPH.2007.123687.

5. Cross TL, Bazron BJ, Dennis KW, Isaacs MR, Benjamin MP. Towards a culturally competent care; A monograph on effective services for minority children who are severely emotionally disturbed. Child Adolesc Serv Syst Progr. 1989:90. https://doi.org/10.1109/55.877196.

6. Education USM. Cultural Competency Training Treating Patients from Different Cultures. Med Educ. 2005;11(December):290-294. https:// doi.org/10.1007/s11116-009-9222-z.

7. Carter MM, Lewis EL, Sbrocco T, et al. Cultural competency training for third-year clerkship students: effects of an interactive workshop on student attitudes. J Natl Med Assoc. 2006;98(11):1772-1778.

8. Committee L on ME. Functions and Structure of a Medical School. 2017.

9. Australian Medical Council. Review of the Standards for Assessment and Accreditation of Primary Medical Programs by the Australian Medical Council. 2017.

10. Beach MC, Price EG, Gary TL, et al. Cultural competence: a systematic review of health care provider educational interventions. Med Care. 2005;43(4):356-373.

11. Popay J, Roberts H, Sowden A, et al. Guidance on the Conduct of Narrative Synthesis in Systematic Reviews. Vol METHODS BR.; 2006. https://doi.org/10.1111/j.1523-536x.1995tb00261.x.

12. Leamy M, Bird V, Le Boutillier C, Williams J, Slade M. Conceptual framework for personal recovery in mental health: Systematic review and narrative synthesis. Br J Psychiatry. 2011;199(6):445-452. https:// doi.org/10.1192/bjp.bp. 110.083733.

13. Ewart, Barry; Sandars J. Community involvement in undergraduate medical education. Clin Teach. 3(3):148-153.

14. Parisi V, Ahmed Z, Lardner D, Cho E. Global health simulations yield culturally competent medical providers. Med Educ. 2012;46(11):11261127. https://doi.org/10.1111/medu. 12012.

15. Kulkarni A, Francis ER, Clark T, Goodsmith N, Fein O. How we developed a locally focused Global Health Clinical Preceptorship at Weill Cornell Medical College. Med Teach. 2014:1-5. https://doi.org/10. 3109/0142159X.2014.886764.

16. Dao DiK, Goss AL, Hoekzema AS, et al. Integrating Theory, Content, and Method to Foster Critical Consciousness in Medical Students: A Comprehensive Model for Cultural Competence Training. Acad Med. 2017;92(3):335-344. https://doi.org/10.1097/ACM. 0000000000001390.

17. J.R. B, M.C. C. Cross-Cultural Medical Education in the United States: Key Principles and Experiences. Kaohsiung J Med Sci. 2009;25(9):471478. https://doi.org/10.1016/S1607-551X(09)70553-4.

18. Kutob RM, Bormanis J, Crago M, Gordon P, Shisslak CM. Using standardized patients to teach cross-cultural communication skills. Med Teach. 2012;34(7):594. https://doi.org/10.3109/0142159X.2012. 675101.

19. Beck BWMBTBSYSAS. Development, Implementation and Evaluation of an M3 Community Health Curriculum. Med Educ Online. 2004;9(1).

20. Crandall SJ, George G, Marion GS, Davis S. Applying theory to the design of cultural competency training for medical students: a case 
study. Acad Med. 2003;78(6):588-594. https://doi.org/10.1097/ 00001888-200306000-00007.

21. Crosson JC, Deng W, Brazeau C, Boyd L, Soto-Greene M. Evaluating the Effect of Cultural Competency Training on Medical Student Attitudes. Fam Med. 2004;36(3): 199-203.

22. Swanberg SM, Abuelroos D, Dabaja E, et al. Partnership for Diversity: A Multidisciplinary Approach to Nurturing Cultural Competence at an Emerging Medical School. Med Ref Serv Q. 2015;34(4):451-460. https://doi.org/10.1080/02763869.2015.1082379.

23. Jarris YS, Bartleman A, Hall EC, Lopez L. A preclinical medical student curriculum to introduce health disparities and cultivate culturally responsive care. J Natl Med Assoc. 2012;104(9-10):404-411. https://doi.org/10.1016/S0027-9684(15)30193-0.

24. Miller E, Green AR. Student reflections on learning cross-cultural skills through a "cultural competence" OSCE. Med Teach. 2007;29(4). https://doi.org/10.1080/01421590701266701.

25. Ho MJ, Gaufberg E, Huang WJ. Problem-based learning: Hidden curricular messages and cultural competence. Med Educ. 2008;42(11):1122-1123. https://doi.org/10.1111/j.1365-2923.2008. 03211.x.

26. Kaul P, Guiton G. Responding to the challenges of teaching cultural competency. Med Educ. 2010;44(5):506. https://doi.org/10.1111/j. 1365-2923.2010.03691.x.

27. Lee AL, Mader EM, Morley CP. Teaching cross-cultural communication skills online: A multi-method evaluation. Fam Med. 2015;47(4):302308.

28. Hawthorne K, Prout H, Kinnersley P, Houston $\mathbf{H}$. Evaluation of different delivery modes of an interactive e-learning programme for teaching cultural diversity. Patient Educ Couns. 2009;74(1):5-11. https://doi.org/10.1016/j.pec.2008.07.056.

29. Whitford DL, Hubail AR. Cultural sensitivity or professional acculturation in early clinical experience? Med Teach. 2014;36(11):951-957. https://doi.org/10.3109/0142159X.2014.910296.

30. Genao I, Bussey-Jones J, St. George DM, Corbie-Smith G. Empowering students with cultural competence knowledge: Randomized controlled trial of a cultural competence curriculum for third-year medical students. J Natl Med Assoc. 2009;101(12):1241-1246. https://doi.org/ 10.1016/S0027-9684(15)31135-4.

31. Bertelsen NS, DallaPiazza M, Hopkins MA, Ogedegbe G. Teaching global health with simulations and case discussions in a medical student selective. Global Health. 2015;11(1). https://doi.org/10.1186/ s12992-015-0111-2.

32. Clementz L, McNamara M, Burt NM, Sparks M, Singh MK. Starting with Lucy: Focusing on Human Similarities Rather Than Differences to Address Health Care Disparities. Acad Med. 2017;92(9):1259-1263. https://doi.org/10.1097/ACM.0000000000001631.

33. Carpenter R, Estrada CA, Medrano M, Smith A, Stanford Massie F. A Web-Based Cultural Competency Training for Medical Students: A Randomized Trial. Am J Med Sci. 2015;349(5):442-446. https://doi. org/10.1097/MAJ.0000000000000351.

34. Hsieh JG, Hsu M, Wang YW. An anthropological approach to teach and evaluate cultural competence in medical students-The application of mini-ethnography in medical history taking. Med Educ Online. 2016;21(1). https://doi.org/10.3402/meo.v21.32561.

35. Addy CL, Browne T, Blake EW, Bailey J. Enhancing interprofessional education: Integrating public health and social work perspectives. Am J Public Health. 2015;105:S106-S108. https://doi.org/10.2105/AJPH. 2014.302502.

36. Ivory $\mathbf{K}$, Bandler $\mathbf{L}$, Hawke $\mathbf{C}$, Armstrong $\mathbf{B}$. A clinical approach to population medicine. Clin Teach. 2013;10(2):94-98. https://doi.org/10. $1111 /$ j.1743-498X.2012.00618.x.

37. Shields HM, Nambudiri VE, Leffler DA, et al. Using Medical Students to Enhance Curricular Integration of Cross-Cultural Content. Kaohsiung J Med Sci. 2009;25(9):493-502. https://doi.org/10.1016/S1607551X(09)70556-X

38. Shellenberger S, Dent MM, Davis-Smith M, Seale JP, Weintraut R, Wright T. Cultural Genogram: A Tool for Teaching and Practice. Fam Syst Heal. 2007;25(4):367-381. https://doi.org/10.1037/1091-7527. 25.4.367.

39. Primack BA, Bui T, Fertman CI. Social marketing meets health literacy: Innovative improvement of health care providers' comfort with patient interaction. Patient Educ Couns. 2007;68(1):3-9. https://doi. org/10.1016/j.pec.2007.02.009

40. Ogur B, Hirsh D, Krupat E, Bor D. The Harvard Medical SchoolCambridge Integrated Clerkship: An innovative model of clinical education. Acad Med. 2007;82(4):397-404. https://doi.org/10.1097/ ACM.0b013e31803338fo.

41. Wilkinson JE. Use of a writing elective to teach cultural competency and professionalism. Fam Med. 2006;38(10):702-704.

42. Carrillo JE, Green AR, Betancourt JR. Cross-cultural primary care: A patient-based approach. Ann Intern Med. 1999;130(10):829-834. https://doi.org/10.7326/0003-4819-130-10-199905180-00017.

43. Singh S, Barua $\mathbf{P}$, Dhaliwal U, Singh $\mathbf{N}$. Harnessing the medical humanities for experiential learning. Indian $J$ Med Ethics. 2017;2(3):147-152. https://doi.org/10.20529/IJME.2017.050.

44. Saypol B, Drossman DA, Schmulson MJ, et al. A review of three educational projects using interactive theater to improve physicianpatient communication when treating patients with irritable bowel syndrome. Rev Esp Enfermedades Dig. 2015;107(5):268-273. https:// www.scopus.com/inward/record.uri?eid=2-s2.0-84945245409\&partnerID=40\&md5=7d124ba7ca3b733f04la6ee735f2303a.

45. Elnashar M, Abdelrahim H, Fetters MD. Cultural competence springs up in the desert: The story of the center for cultural competence in health care at Weill Cornell Medical College in Qatar. Acad Med. 2012;87(6):759766. https://doi.org/10.1097/ACM.0b013e318253d6c6.

46. Knipper M, Seeleman IC, Essink ML. How should ethnic diversity be represented in medical curricula? A plea for systematic training in cultural competence. Tijdschrift voor Medisch Onderwijs. 2010:1-7.

47. Thompson BM, Haidet P, Casanova R, et al. Medical students' perceptions of their teachers' and their own cultural competency: implications for education. J Gen Intern Med. 2010;25 Suppl 2(Suppl 2):S91-4. https://doi.org/10.1007/s11606-009-1245-9.

48. Lypson ML, Ross PT, Kumagai AK. Medical students' perspectives on a multicultural curriculum. J Natl Med Assoc. 2008;100(9):1078-1083. https://doi.org/10.1016/S0027-9684(15)31448-6.

49. McDonald M, West J, Israel T. From Identification to Advocacy: A Module for Teaching Social Determinants of Health. MedEdPORTAL Publ. 2015. https://doi.org/10.15766/mep_2374-8265.10266.

50. Kodjo C, Lee B, Morgan A, et al. Twist on Cultural Sensitivity. MedEdPORTAL Publ. 2014. https://doi.org/10.15766/mep_23748265.9931

51. Stuart E, Bereknyei S, Long M, Blankenburg R, Weak V, Garcia R. Standardized Patient Cases for Skill Building in Patient-centered, Cross-cultural Interviewing (Stanford Gap Cases). MedEdPORTAL Publ. 2014. https://doi.org/10.15766/mep_2374-8265.9133.

52. Fredrick N. Teaching Social Determinants of Health Through MiniService Learning Experiences. MedEdPORTAL Publ. 2014. https://doi. org/10.15766/mep_2374-8265.9056.

53. Elliott D, George C, Signorelli D, Trial J. Stereotypes and Bias at the Psychiatric Bedside-Cultural Competence in the Third Year Required Clerkships. MedEdPORTAL Publ. 2014. https://doi.org/10.15766/ mep_2374-8265.1150.

54. Elson M. Cultural Sensitivity in OB/GYN: the Ultimate PatientCentered Care. MedEdPORTAL Publ. 2014. https://doi.org/10.15766/ mep_2374-8265.1658.

55. DeGannes $\mathbf{C}$, Woodson Coke $\mathbf{K}$, Sanders-Phillips $\mathbf{K}$, Henderson $\mathbf{T}$. A Small-Group Reflection Exercise for Increasing the Awareness of Cultural Stereotypes: A Facilitator's Guide. MedEdPORTAL Publ. 2014. https://doi.org/10.15766/mep_2374-8265.668.

56. Kobylarz F, Heath J, Like R, Granville L. The ETHNICS Mnemonic: Clinical Tool, Didactics, and Small Group Facilitator's Guide. MedEdPORTAL Publ. 2014. https://doi.org/10.15766/mep 2374-8265.600.

57. Bower D, Webb T, Larson G, et al. Patient Centered Care Workshop: Providing Quality Health Care to a Diverse Population. MedEdPORTAL Publ. 2014. https://doi.org/10.15766/mep_2374-8265.579.

58. Crandall s. Elective Course in Culture and Diversity. MedEdPORTAL Publ. 2014. https://doi.org/10.15766/mep_2374-8265.192.

59. Elliott D, Schaff P, Woehrle T, Walsh A, Trial J. Narrative Reflection in Family Medicine Clerkship-Cultural Competence in the Third Year Required Clerkships. MedEdPORTAL Publ. 2014. https://doi.org/10. 15766/mep_2374-8265.1153.

60. Kutscher E, Boutin-Foster C. Community Perspectives in Medicine: Elective for First-Year Medical Students. MedEdPORTAL Publ. 2016;122. https://doi.org/10.15766/mep_2374-8265.10501.

61. Gill A, Thompson B, Teal C, et al. Best Intentions: Using the Implicit Associations Test to Promote Reflection About Personal Bias. MedEdPORTAL Publ. 2014. https://doi.org/10.15766/mep_2374-8265.7792.

62. Lypson M, Perlman R, Silveria M, Lash R, Johnson C. The Social History...It's About the Patient-Culture and All. MedEdPORTAL Publ. 2014. https://doi.org/10.15766/mep_2374-8265.3149. 
63. Elliott D. Cultural Self Awareness Workshop. MedEdPORTAL Publ. 2014. https://doi.org/10.15766/mep_2374-8265.1128.

64. Blue A. Cultural Competency Interviewing Case Using the ETHNIC Mnemonic. MedEdPORTAL Publ. 2014. https://doi.org/10.15766/mep 2374-8265. 155.

65. Drake C, Keeport M, Chapman A, Chakraborti C. Social Contexts in Medicine: A Patient-Centered Curriculum Empowering Medical Students to Provide Contextualized Care. MedEdPORTAL Publ. 2017;13. https://doi.org/10.15766/mep_2374-8265.10541.

66. Bereknyei S, Foran S, Scott A, Braddock C, Johnson $\mathbf{K}$, Miller $\mathbf{T}$ Stopping Discrimination Before it Starts: The Impact of Civil Rights Laws on Healthcare Disparities-A Medical School Curriculum. MedEd PORTAL Publ. 2014. https://doi.org/10.15766/mep_2374-8265.7740.

67. Allwardt D. Culturally Competent Health Care Practice with Older Adults. MedEdPORTAL Publ. 2014. https://doi.org/10.15766/mep_ 2374-8265.254

68. Martinez I, Ilangovan $\mathbf{K}$, Whisenant E, Pedoussaut M, Lage O. Breast Health Disparities: A Primer for Medical Students. MedEdPORTAL Publ. 2016;12. https://doi.org/10.15766/mep_2374-8265.10471.

69. Hafner C. Introduction to Traditional Chinese Medicine (Out of Print). MedEdPORTAL Publ. 2014. https://doi.org/10.15766/mep_2374-8265. 221

70. Denson K. Virtual Patient Case \#4: Mrs. Violetta Mitsuko Tang-Chief Diagnosis: Osteoporosis/Incontinence. MedEdPORTAL Publ. 2014. https://doi.org/10.15766/mep_2374-8265.136.

71. Whitney Ann Cesari, William F. Brescia PhD, Kabir Harricharan Singh, Adeleke Oni, Anureet Cheema, Catherine Coffman, Aaron Creek, Crisanto Torres, Marissa Mencio, Stacy Clayton, Carmen Weaver JW. Medical Spanish. MedEdPORTAL Publ. 2012;8(9171).

72. Muntean V, Calinici T, Tigan S, Fors UGH. Language, culture and international exchange of virtual patients. BMC Med Educ. 2013;13(1). https://doi.org/10.1186/1472-6920-13-21.

73. Zhang C, Cho K, Chu J, Yang J. Bridging the gap: Enhancing cultural competence of medical students through online videos. J Immigr Minor Heal. 2014;16(2):326-327. https://doi.org/10.1007/s10903-0129755-7.

74. Kron FW, Fetters MD, Scerbo $\mathbf{M W}$, et al. Using a computer simulation for teaching communication skills: A blinded multisite mixed methods randomized controlled trial. Patient Educ Couns. 2017;100(4):748-759. https://doi.org/10.1016/j.pec.2016.10.024.

75. Mihalic AP, Morrow JB, Long RB, Dobbie AE. A validated cultural competence curriculum for US pediatric clerkships. Patient Educ Couns. 2010;79(1):77-82. https://doi.org/10.1016/j.pec.2009.07.029.

76. Lee WWVJN. Medical School Hotline: Promoting Diversity of the Health Care Workforce. Hawaii Med J. 2010;5(1):130-131

77. Sopoaga F, Zaharic T, Kokaua J, Covello S. Training a medica workforce to meet the needs of diverse minority communities. BMC Med Educ. 2017;17(1). https://doi.org/10.1186/s12909-017-0858-7.

78. Mak DB, Miflin B. Living and working with the people of "the bush": A foundation for rural and remote clinical placements in undergraduate medical education. Med Teach. 2012;34(9). https://doi.org/10.3109/ 0142159X.2012.670326.

79. Morell Vw, Sharp PC, Crandall SJ. Creating student awareness to improve cultural competence: creating the critical incident. Med Teach 2002;24(5):532-534. https://doi.org/10.1080/0142159021000012577.

80. Pinnock R, Jones R, Wearn A. Learning and assessing cultural competence in paediatrics. Med Educ. 2008;42(11):1124-1125. https://doi.org/10.1111/j.1365-2923.2008.03213.x.

81. Hudson GL, Maar M. Faculty analysis of distributed medical education in Northern Canadian Aboriginal communities. Rural Remote Health. 2014; 14(4).

82. Huria T, Palmer S, Beckert L, Lacey C, Pitama S. Indigenous health: Designing a clinical orientation program valued by learners. BMC Med Educ. 2017;17(1). https://doi.org/10.1186/s12909-017-1019-8.

83. Smith JD, Wolfe C, Springer S, et al. Using cultural immersion as the platform for teaching Aboriginal and Torres Strait Islander health in an undergraduate medical curriculum. Rural Remote Health. 2015;15(3):3144.

84. Carpenter D-AL, Kamaka ML, Kaulukukui CM. An innovative approach to developing a cultural competency curriculum; efforts at the John A. Burns School of Medicine, Department of Native Hawaiian Health. Hawaii Med J. 2011;70(11 Suppl 2):15-19. http://search ebscohost.com/login.aspx?direct=true $\& \mathrm{db}=\mathrm{mnh} \& \mathrm{AN}=22235152 \&$ si te $=$ ehost-live.
85. Kumagai AK, Kakwan M, Sediqe S, Dimagno MM. Actors' personal stories in case-based multicultural medical education. Med Educ. 2010;44(5):506507. https://doi.org/10.1111/j.1365-2923.2010.03672.x.

86. Topping D. An interprofessional education Russian cultural competence course: Implementation and follow-up perspectives. $J$ Interprof Care. 2015;29(5):501-503. https://doi.org/10.3109/13561820.2015. 1012582.

87. Ziganshin BA, Yausheva LM, Sadigh M, et al. Training Young Russian Physicians in Uganda: A Unique Program for Introducing Global Health Education in Russia. Ann Glob Heal. 2015;81(5):627-635. https://doi. org/10.1016/j.aogh.2015.10.007

88. Bruno DM, Imperato PJ. A Global Health Elective for US Medical Students: The 35 Year Experience of the State University of New York, Downstate Medical Center, School of Public Health. J Community Health. 2015;40(2):187-198. https://doi.org/10.1007/s10900-0149981-0.

89. Jordan J, Hoffman R, Arora G, Coates W. Activated learning; providing structure in global health education at the David Geffen School of Medicine at the University of California, Los Angeles (UCLA)—a pilot study. BMC Med Educ. 2016;16(1):63. https://doi.org/10.1186/ s12909-016-0581-9.

90. Allison J, Mulay S, Kidd M. Life in unexpected places: Employing visual thinking strategies in global health training. Educ Heal Chang Learn Pract. 2017;30(1):64-67. https://doi.org/10.4103/1357-6283.210511.

91. Green SS, Comer L, Elliott L, Neubrander J. EXPLORING the Value of an International Service-Learning EXPERIENCE in Honduras. Nurs Educ Perspect. 2011;32(5):302-307. https://doi.org/10.5480/15365026-32.5.302.

92. Godkin M, Savageau J. The effect of medical students' international experiences on attitudes toward serving underserved multicultural populations. Fam Med. 2003;35(4):273-278.

93. Godkin MA, Savageau JA. The effect of a global multiculturalism track on cultural competence of preclinical medical students. Fam Med. 2001;33(3):178-186

94. Mao JJ, Wax J, Barg FK, Margo K, Walrath D. A gain in cultural competence through an international acupuncture elective. Fam Med. 2007;39(1):16-18.

95. Knipper M, Baumann A, Hofstetter C, Korte R, Krawinkel M. Internationalizing Medical Education: The Special Track Curriculum "Global Health" at Justus Liebig University Giessen. GMS Zeitschrift für medizinische Ausbildung. 2015;32(5):Doc52. https://doi.org/10.3205/ zma000994.

96. Nishigori H, Otani T, Plint S, Uchino M, Ban N. I came, I saw, I reflected: A qualitative study into learning outcomes of international electives for Japanese and British medical students. Med Teach. 2009;31(5). https://doi.org/10.1080/01421590802516764.

97. Hutchins FT, Brown LD, Poulsen KP. An anthropological approach to teaching health sciences students cultural competency in a field school program. Acad Med. 2014;89(2):251-256. https://doi.org/10.1097/ ACM.0000000000000088.

98. Jacobs F, Stegmann K, Siebeck M. Promoting medical competencies through international exchange programs: Benefits on communication and effective doctor-patient relationships. BMC Med Educ. 2014;14(1). https://doi.org/10.1186/1472-6920-14-43.

99. John C, Asquith H, Wren T, Mercuri S, Brownlow S. A student-led global health education initiative: Reflections on the Kenyan village medical education program. J Public health Res. 2016;5(1):7-9. https:// doi.org/10.4081/jphr.2016.646.

100. Holmes D, Zayas LE, Koyfman A. Student objectives and learning experiences in a global health elective. $J$ Community Health. 2012;37(5):927-934. https://doi.org/10.1007/s10900-012-9547-y.

101. Lee P, Johnson A, Rajashekara S, et al. Clinical Topics in Global Health: A Practical Introduction for Pre-Clinical Medical Students. MedEdPORTAL Publ. 2014. https://doi.org/10.15766/mep 23748265.9471

102. Turner JL, Farquhar L. One medical school's effort to ready the workforce for the future: Preparing medical students to care for populations who are publicly insured. Acad Med. 2008;83(7):632-638. https://doi.org/10.1097/ACM.0b013e31817836af.

103. Smith-Campbell B. Health professional students' cultural competence and attitudes toward the poor: The influence of a clinical practicum supported by the national health service corps. J Allied Health. 2005;34(1):56-62.

104. Sheu L, Lai CJ, Coelho AD, et al. Impact of Student-Run Clinics on Preclinical Sociocultural and Interprofessional Attitudes: A Prospective 
Cohort Analysis. J Health Care Poor Underserved. 2012;23(3):10581072. https://doi.org/10.1353/hpu.2012.0101.

105. Bullock K, Jackson BR, Lee J. Engaging communities to enhance and strengthen medical education: Rationale and summary of experience. World Med Heal Policy. 2014;6(2):133-141. https://doi.org/10.1002/ wmh3.94.

106. Wong Jw. Medical School Hotline: Cultural Competency in Serving the Homeless in Hawaiti at the John A. Burns School of Medicine. Hawaii J Med Public Health. 2016;75(1):18-21.

107. Pickrell J, Spector G, Chi D, Riedy C. Working Together to Access Dental Care for Young Underserved Children: A Problem-Based Learning Approach to Increase Health Professional Students Awareness. MedEdPORTAL Publ. 2014. https://doi.org/10.15766/mep_23748265.9380.

108. Lie D, Bereknyei S, Braddock CH, Encinas J, Ahearn S, Boker JR Assessing medical students' skills in working with interpreters during patient encounters: A validation study of the interpreter scale. Acad Med. 2009;84(5):643-650. https://doi.org/10.1097/ACM. Ob013e31819faec8.

109. Azam S, Carroll M. Enhancing students' communication in an ethnic language. Med Educ. 2013;47(11):1144-1145. https://doi.org/10. $1111 /$ medu. 12345

110. Xiao W, Chen X, Chen M, Liao R. Developing cross-cultural competence in Chinese medical students. Med Teach. 2013;35(9):788-789. https://doi.org/10.3109/0142159X.2013.786178.

111. Fung CC, Lagha RR, Henderson P, Gomez AG. Working with interpreters: how student behavior affects quality of patient interaction when using interpreters. Med Educ Online. 2010;15. https://doi.org/ 10.3402/meo.v15i0.5151.

112. Lie D, Boker J, Bereknyei S, Ahearn S, Fesko C, Lenahan P Validating measures of third year medical students' use of interpreters by standardized patients and faculty observers. $J$ Gen Intern Med. 2007;22(SUPPL. 2):336-340. https://doi.org/10.1007/s11606-0070349-3.

113. Lie DA, Bereknyei S, Vega CP. Longitudinal development of medical students' communication skills in interpreted encounters. Educ Heal Chang Learn Pract. 2010;23(3):466. https://login.ezproxy.net.ucf.edu/ login?auth=shibb\&url=http://search.ebscohost.com/login.aspx?direct $=$ true $\& \mathrm{db}=$ cmedm $\& A N=21290365 \&$ site $=$ ehost-live $\% 5$ Cnhttps: $/ / \operatorname{logi}$ n.ezproxy.net.ucf.edu/login?auth=shibb\&url=http://search.ebscohost.com/login.aspx?direct=true $\& \mathrm{db}=$.

114. McEvoy M, Santos MT, Marzan M, Green EH, Milan FB. Teaching medical students how to use interpreters: a three year experience. Med Educ Online. 2009;14:12. https://doi.org/10.3885/meo.2009. Res00309.

115. Zanetti ML, Godkin MA, Twomey JP, Pugnaire MP. Global longitudinal pathway: Has medical education curriculum influenced medical students' skills and attitudes toward culturally diverse populations? Teach Learn Med. 2011;23(3):223-230. https://doi.org/10.1080/ 10401334.2011.586913.

116. Nora LM, Daugherty SR, Mattis-Peterson a, Stevenson L, Goodman LJ. Improving cross-cultural skills of medical students through medical school-community partnerships. West $J$ Med. 1994;161(2): 144-147.

117. Dawson A, Patti B. Spanish Acquisition Begets Enhanced Service (S.A.B.E.S.): A Beginning-Level Medical Spanish Curriculum. MedEd PORTAL Publ. 2014. https://doi.org/10.15766/mep_2374-8265.9057.

118. Trial J, Elliott D, Lauzon V, Lie D, Chvira E Interpretation at the OB/ GYN Bedside-Cultural Competence in the Third Year Clerkships. MedEdPORTAL Publ. 2014. https://doi.org/10.15766/mep_23748265.1148

119. Waldman S, Kalet A. Working With Interpreters: Learning To Conduct A Cross-Language Medical Interview With An Online Web-Based Module (Out of Print). MedEdPORTAL Publ. 2014. https://doi.org/10.15766/ mep_2374-8265.654

120. Lie D. Interpreter Cases for Cultural Competency Instruction. MedEd PORTAL Publ. 2014. https://doi.org/10.15766/mep_2374-8265.205.

121. Asgary R, Saenger P, Jophlin L, Burnett DC. Domestic Global Health: A Curriculum Teaching Medical Students to Evaluate Refugee Asylum Seekers and Torture Survivors. Teach Learn Med. 2013;25(4):348-357. https://doi.org/10.1080/10401334.2013.827980.

122. Knipper M, Akinci S, Soydan N. Culture and healthcare in medical education: migrants' health and beyond. GMS Z Med Ausbild. 2010;27(3):Doc41. https://doi.org/10.3205/zma000678.

123. Albritton TA, Wagner PJ. Linking Cultural Competency and Community Service: A Partnership between Students, Faculty, and the
Community. Acad Med. 2002;77(7):738-739. https://doi.org/10. 1097/00001888-200207000-00024.

124. Griswold K, Kernan JB, Servoss TJ, Saad FG, Wagner CM, Zayas LE. Refugees and medical student training: Results of a programme in primary care. Med Educ. 2006;40(7):697-703. https://doi.org/10. $1111 /$ j.1365-2929.2006.02514.x.

125. Stone H, Choi R, Aagaard E, et al. Refugee Health Elective. MedEdPORTAL Publ. 2014. https://doi.org/10.15766/mep_2374-8265.9457.

126. DeFries T, Rodrigues M, Ghorob A, Handley M. Health Communication and Action Planning with Immigrant Patients: Aligning Clinician and Community Perspectives. MedEdPORTAL Publ. 2015. https://doi. org/10.15766/mep_2374-8265.10050.

127. Woodard LJ, Havercamp SM, Zwygart KK, Perkins EA. An innovative clerkship module focused on patients with disabilities. Acad Med. 2012;87(4):537-542. https://doi.org/10.1097/ACM.0b013e318248ed0a.

128. Jain Dr. S, Foster E, Biery N, Boyle V. Patients with disabilities as teachers. Fam Med. 2013;45(1):37-39.

129. Rossignol L. Relationship between Participation in Patient- and FamilyCentered Care Training and Communication Adaptability among Medical Students: Changing Hearts, Changing Minds. Perm J. 2015. https://doi.org/10.7812/TPP/14-110.

130. Eddey GE, Robey KL. Considering the culture of disability in cultural competence education. Acad Med. 2005;80(7):706-712. https://doi. org/10.1097/00001888-200507000-00019.

131. Hagood JS, Lenker C V, Thrasher S. A course on the transition to adult care of patients with childhood-onset chronic illnesses. Acad Med. 2005;80(4):352-355. https://doi.org/10.1097/00001888-20050400000009 .

132. Hoang L, LaHousse SF, Nakaji MC, Sadler GR. Assessing deaf cultural competency of physicians and medical students. In: Journal of Cancer Education. Vol 26. 2011:175-182. https://doi.org/10.1007/s13187010-0144-4.

133. Thew D, Smith SR, Chang C, Starr M. The deaf strong hospital program: a model of diversity and inclusion training for first-year medical students. Acad Med. 2012;87(11):1496-1500. https://doi.org/ 10.1097/ACM.0b013e31826d322d

134. Lapinski J, Colonna C, Sexton P, Richard M. American Sign Language and Deaf Culture Competency of Osteopathic Medical Students. Am Ann Deaf. 2015;160(1):36-47. https://doi.org/10.1353/aad.2015. 0014

135. Bradford N, Mulroy B. Medical Students as Coaches in Transitions of Care for Youth with Special Health Care Needs. MedEdPORTAL Publ. 2015. https://doi.org/10.15766/mep_2374-8265.10183.

136. Rogers J, Morris M, Hook C, Havyer R. Introduction to Disability and Health for Preclinical Medical Students: Didactic and Disability Panel Discussion. MedEdPORTAL Publ. 2016;12. https://doi.org/10.15766/ mep_2374-8265.10429.

137. Stoller L, Fowler M. Spiritual Histories: Putting Religio-Cultural Competence into Practice. MedEdPORTAL Publ. 2015. https://doi.org/ 10.15766/mep_2374-8265.10029.

138. Stoller L, Blanchard E, Fowler M. Trigger Topics: Where Religion \& Health Care Intersect. MedEdPORTAL Publ. 2015. https://doi.org/10. 15766/mep 2374-8265.10007.

139. Spike J, Rousso J. Starchild Cherrix: Negotiating about Religious Beliefs and Complementary and Alternative Medicine. MedEdPORTAL Publ. 2014. https://doi.org/10.15766/mep_2374-8265.3164.

140. Leonard B. Spirituality in Healthcare (Out of Print). MedEdPORTAL Publ. 2014. https://doi.org/10.15766/mep_2374-8265.208.

141. Lubimir KT, Wen AB. Towards cultural competency in end-of-life communication training. Hawaii Med J. 2011;70(11):239-241. http: / / www.pubmedcentral.nih.gov/articlerender.fcgi? artid=32 15988\&tool=pmcentre $\&$ \&rendertype=abstract.

142. Ellman MS, Schulman-Green D, Blatt L, et al. Using Online Learning and Interactive Simulation To Teach Spiritual and Cultural Aspects of Palliative Care to Interprofessional Students. J Palliat Med. 2012;15(11):1240-1247. https://doi.org/10.1089/jpm.2012.0038.

143. Murphy-Shigematsu S, Grainger-Monsen $\mathbf{M}$. The impact of film in teaching cultural medicine. Fam Med. 2010;42(3):170-172.

144. Daly M, Perkins D, Kumar K, Roberts C, Moore M. What factors in rural and remote extended clinical placements may contribute to preparedness for practice from the perspective of students and clinicians? Med Teach. 2013;35(11):900-907. https://doi.org/10.3109/ 0142159X.2013.820274.

145. Brumby SA, Ruldolphi J, Rohlman D, Donham KJ. Translating agricultural health and medicine education across the Pacific: A United 
States and Australian comparison study. Rural Remote Health 2017;17(1). https://doi.org/10.22605/RRH3931.

146. Keys III R, Desnick L, Bienz D, Evans D. Public Health Community Externship. MedEdPORTAL Publ. 2015. https://doi.org/10.15766/ mep_2374-8265.10260.

147. Vanderleest JG, Galper CQ. Improving the Health of Transgender People: Transgender Medical Education in Arizona. $J$ Assoc Nurses AIDS Care. 2009;20(5):411-416. https://doi.org/10.1016/j.jana.2009.07.003.

148. Neff A, Kingery S. Complete Androgen Insensitivity Syndrome: A Problem-Based Learning Case. MedEdPORTAL Publ. 2016;12. https:// doi.org/10.15766/mep_2374-8265.10522

149. Jin H, Dasgupta S. Genetics in LGB Assisted Reproduction: Two Flipped Classroom, Progressive Disclosure Cases. MedEdPORTAL Publ. 2017; 13. https://doi.org/10.15766/mep_2374-8265.10607.

150. Curren C, Thompson L, Altneu E, Tartaglia K, Davis J. Nathan/ Natalie Marquez: A Standardized Patient Case to Introduce Unique Needs of an LGBT patient. MedEdPORTAL Publ. 2015. https://doi.org/ 10.15766/mep_2374-8265.10300.

151. Gallego J, Knudsen J. LGBTQI* Defined: An Introduction to Understanding and Caring for the Queer Community. MedEdPORTAL Publ. 2015. https://doi.org/10.15766/mep_2374-8265.10189.

152. Gelman A, Amin P, Pletcher J, Fulmer V, Kukic A, Spagnoletti C. A Standardized Patient Case: A Teen Questioning His/Her Sexuality is Bullied at School. MedEdPORTAL Publ. 2014. https://doi.org/10. 15766/mep_2374-8265.9876.

153. Mehringer J, Bacon E, Cizek S, Kanters A, Fennimore T. Preparing Future Physicians to Care for LGBT Patients: A Medical School Curriculum. MedEdPORTAL Publ. 2014. https://doi.org/10.15766/ mep_2374-8265.9342.

154. Sullivan W, Eckstrand K, Rush C, Peebles K, Lomis K, Fleming A. An Intervention for Clinical Medical Students on LGBTI Health. MedEdPORTAL Publ. 2014. https://doi.org/10.15766/mep_2374-8265.9349.

155. Croft C, Pletcher J, Fulmer V, Steele R, Day H, Spagnoletti C. A Same-Sex Couple Copes with End-of-Life Issues: A Case Materials Guide. MedEdPORTAL Publ. 2014. https://doi.org/10.15766/mep_ 2374-8265.9438.

156. Sell J, George D, Levine M. HIV: A Socioecological Case Study. MedEdPORTAL Publ. 2016;12. https://doi.org/10.15766/mep_23748265. 10509 .

157. Leslie K, Steinbock S, Simpson R, Jones VF, Sawning S. Interprofessional LGBT Health Equity Education for Early Learners. MedEdPORTAL Publ. 2017;13. https://doi.org/10.15766/mep_2374-8265. 10551.

158. Gacita A, Gargus E, Uchida T, et al. Introduction to Safe Space Training: Interactive Module for Promoting a Safe Space Learning Environment for LGBT Medical Students. MedEdPORTAL Publ. 2017;13. https://doi.org/10.15766/mep_2374-8265.10597.
159. Calzo J, Melchiono M, Richmond T, et al. Lesbian, Gay, Bisexual, and Transgender Adolescent Health: An Interprofessional Case Discussion. MedEdPORTAL Publ. 2017;13. https://doi.org/10.15766/mep_23748265.10615.

160. Potter L, Burnett-Bowie S-A, Potter J. Teaching Medical Students How to Ask Patients Questions About Identity, Intersectionality, and Resilience. MedEdPORTAL Publ. 2016;12. https://doi.org/10.15766/ mep_2374-8265.10422.

161. Bakhai N, Shields R, Barone M, Sanders R, Fields E. An Active Learning Module Teaching Advanced Communication Skills to Care for Sexual Minority Youth in Clinical Medical Education. MedEdPORTAL Publ. 2016;12. https://doi.org/10.15766/mep_2374-8265.10449.

162. Bakhai N, Ramos J, Gorfinkle N, et al. Introductory Learning of Inclusive Sexual History Taking: An E-Lecture, Standardized Patient Case, and Facilitated Debrief. MedEdPORTAL Publ. 2016;12. https:// doi.org/10.15766/mep_2374-8265.10520.

163. Lee R, Loeb D, Butterfield A. Sexual History Taking Curriculum: Lecture and Standardized Patient Cases. MedEdPORTAL Publ. 2014;10. https://doi.org/10.15766/mep_2374-8265.9856.

164. Gozu A, Beach MC, Price EG, et al. Self-administered instruments to measure cultural competence of health professionals: A systematic review. Teach Learn Med. 2007;19(2):180-190. https://doi.org/10. 1080/10401330701333654.

165. Price EG, Beach MC, Gary TL, et al. A systematic review of the methodological rigor of studies evaluating cultural competence training of health professionals. Acad Med. 2005;80(6):578-586. https://doi. org/10.1097/00001888-200506000-00013

166. Zinski A, Blackwell KTCPW, Belue FM, Brooks WS. Is lecture dead? A preliminary study of medical students' evaluation of teaching methods in the preclinical curriculum. Int J Med Educ. 2017;8:326-333. https:// doi.org/10.5116/ijme.59b9.5f40.

167. Graffam B. Active learning in medical education: Strategies for beginning implementation. Med Teach. 2007;29(1):38-42. https://doi. org/10.1080/01421590601176398.

168. Barrows HS. Problem-based learning in medicine and beyond: A brief overview. New Dir Teach Learn. 1996;1996(68):3-12. https://doi.org/ $10.1002 / \mathrm{tl} .37219966804$.

169. Jernigan VBB, Tran K, Norris KC. An Examination of Cultural Competence Training in US Medical Education Guided by the Tool for Assessing Cultural Competence Training. J Heal Disparities Res Pract $J$ Heal Disparities Res Pract J Heal Disparities Res Pract. 2016;9(3):150167. https://doi.org/10.1038/nbt.3121.ChIP-nexus.

Publisher's Note Springer Nature remains neutral with regard to jurisdictional claims in published maps and institutional affiliations. 